Current Research in Psychology 1 (1): 61-66, 2010

ISSN 1949-0178

(C) 2010 Science Publications

\title{
The Relationship between Gender, Age, Depression and Academic Achievement
}

\author{
${ }^{1}$ Fayegh Yousefi, ${ }^{2}$ Mariani Bte Mansor, ${ }^{2}$ Rumaya Bte Juhari, ${ }^{2}$ Ma rof Redzuan and ${ }^{2}$ Mansor Abu Talib \\ ${ }^{1}$ Department of Psychiatry, Faculty of Medicine, Kurdistan University of Medical Science, Sanandaj, Iran \\ ${ }^{2}$ Department of Human Development and Family Studies, University Putra Malaysia, \\ Serdang 43400, Malaysia
}

\begin{abstract}
Problem statement: Depression is said to have a relationship with academic achievement. Thus, the purpose of the study was to investigate the relationship between age, depression and academic achievement among adolescents. Approach: The study was carried out among 400 students (200 boys and 200 girls) in the age range 15-19 years. The instrument used for data collection was the Beck Depression Inventory (21 item BDI). The analysis of data used correlation coefficient and t-test. Results: The results showed that $27.5 \%$ of the boys and $31.5 \%$ of the girls were depressed and that depression and academic achievement were significantly correlated, $\mathrm{r}=-0.22, \mathrm{p} \leq 0.000$. Also, based on results of the present study, age and academic achievement were significantly correlated $(r=0.23$, $\mathrm{p} \leq 0.000$ ). In addition there was significant difference of academic achievement between male and female, $(\mathrm{t}(1)=-5.47, \mathrm{p}=0.000)$. Conclusion/Recommendations: It is recommended that along with academic achievement, mental health be developed in school settings using support strategies such as educational guidance and counseling, teaching life skill programs and psychotherapy.
\end{abstract}

Key words: Depression, academic achievement, age and gender

\section{INTRODUCTION}

The next two decades may witness world-wide changes in the epidemiological pattern of diseases. Non-communicable diseases such as mental disorders may replace infectious and communicable diseases as the leading factor in disability and premature death. Already there are around 52 million people in the world suffering from severe mental health disorders such as schizophrenia, while 150 million have mild mental disorders such as depression and anxiety, 120 million people have mental retardation, 50 million epilepsy and 30 million have dementias Modabber-Nia et al. (2007).

According to American Psychiatric Association (2009), mood refers to a sustained emotion that colors the way people view life. Recognizing mood disorders is important, because as many as $20 \%$ women and $10 \%$ men may have one. Their prevalence seems to be increasing in both sexes and they account for as much as $50 \%$ of a typical mental health practice.

One of the mental disorders which have a particularly high prevalence is depression. Based on WHO information cited in Modabber-Nia et al. (2007), depressive disorders are the fourth leading health problem in the world. This suggests that depressive disorders may become the second most disabling disease of mankind by the year 2020. Also, Khayerabadi and Yousefi (2000) reported that $35.7 \%$ of Kurdistan population with above 15 years age has depression.

Adolescent depression, a disorder occurring during the teenage years, is marked by persistent sadness, discouragement, loss of self-worth and interest in daily activities. True depression in teens is often difficult to diagnose because normal adolescent behavior is marked by both up and down moods due to the hormonal changes teens experience (Mackenzie et al., 2001). Hallfors et al. (2005); who were responsible for the National Survey on Drug Use and Health in Research Triangle Park, North Carolina, estimated that $14 \%$ of adolescents aged 12-17 (approximately 3.5 million adolescents) had experienced at least one Major Depressive Episode (MDE) in their lifetime and that 9.0\% (2.2 million adolescents) had also experienced at least one MDE in the past one year. Adolescents aged 16 or 17 had more depression in the past year compared with adolescents aged 12 or 13 (12.3 Vs 5.4\%).

Yet others have noted a depression rate of $34 \%$ amongst adolescents (Modabber-Nia et al., 2007; Moritz et al., 2003; Winter and Bowers, 2007).

Corresponding Author: Ma'rof Redzuan, Department of Human Development and Family Studies, University Putra Malaysia, Serdang43400, Malaysia Tel; +123484810 
Modabber-Nia et al. (2007), in their study on depression in Iran, indicated that $34 \%$ of high school students suffered from depression. According to their findings, $25 \%$ of male and $39 \%$ of female students had depressive symptoms. Hosseini and Mousavi (2004) found that $44.3 \%$ of students in Iran had depression. By comparison, Hosseini and Mousavi (2004) showed $10.5 \%$ of respondents had mental disorders, especially depression, Masood Zadeh ( 2002) showed 39.1\% of high school students had depression and Khayerabadi and Yousefi (2000) found 35.7\% of Kurdistan people had mental problems. In addition, Sharifi (2001) showed $46 \%$ of high school students had depression in a study done in Sanandaj City, Iran. While, Tavakeli (2000) found $17 \%$ of high school students had severe depression, 30\% had moderate depression and 35\% of those respondents had mild depression in Kurdistan.

So, Sharifi (2001) indicated that 17, 44 and 17\% of high school students in Sanandaj were severe, moderate and mild depression respectively. As mentioned above, depression affects academic achievement. According to Chen and LI (2000), adolescents with depression are vulnerable to educational underachievement. Also, using information based on a resource allocation model of the effect of a depressed mood on cognition, students with symptoms of depression are predisposed to focus their attention on interfering, irrelevant thoughts, leaving little sustained attention available for cognitive tasks which then leads to academic failure. For example, Frojd et al. (2008) reported that depression impair cognitive functioning and blocks cognitive sources and many of the academic performance and also homework depend on the ability to sustain attention and concentration. Thus depression, which is known to disrupt concentration and attention in school, is likely to undermine academic performance. Research indicates, then, that a depressed mood is negatively related to academic achievement.

The educational system tem is vital for every country in the world and Iran is no exception; a strong and effective education system can help boost the development of the country. Many researchers have witnessed tremendous academic failures among the students in Iran and some have tried to find the reasons behind the alarming rate of failures. Searching to identify the variables related to the causes of this problem. The major purpose of this current study was to investigate the relationship between depression and academic achievements in adolescents. This research was different from other studies conducted before, as it linked academic achievement, depression and adolescents.

Fergusson and Horwood (1997) in their study with 1000 respondents between 8-18 years old in New Zealand reported that there were differences of school achievement between male and female, mean that, males having lower scores than females in all standardized tests. Linver et al. (2002) in their study with 1821 respondents among adolescents from USA, found that girls have slightly higher grades than boys. Furthermore, Anne-Rampacher and Peterson (1999) showed that age has impact on academic achievement among students.

\section{MATERIALS AND METHODS}

Participants: The sample of the current study was 400 adolescent students (200 boys and 200 girls in the range of 15-19 years). The population in the current study was comprised of two numbers of subgroups, particularly gender and age, given the possibility that they may have differed in the traits being studied, so, as it is often recommended to utilize stratified random sampling (Gravette and Forzano, 2006), this was the method used.

The procedure for choosing the total number involved three stages:

- Nine public high schools and pre-university schools were selected from among a number of high schools and pre-university schools having adolescence students in Sanandaj by simple random sampling

- The total number of students according to their age and gender was determined and then by ratio formula (in arithmetic, proportion is the equality of ratios; ratio is the division of one number by another) in each of the high schools and preuniversity schools the number of samples was selected. Then, the actual respondents were selected by simple random sampling

- The two subgroups (age groups and gender) were combined into the overall samples

Measure: Depression was measured using the responses to the beck depression inventory. The respondents of the study were asked to answer each of the questions expressing their current feeling.

It needs to be mentioned that the internal consistency for the BDI ranges from 0.73-0.92 with a mean of 0.86 (Beck et al., 1988). Similar reliabilities have been found for the 13 item short form (Groth- 
Marnat, 2003). The BDI demonstrates high internal consistency with an alpha co-efficient of 0.86 and 0.81 for psychiatric and non-psychiatric populations respectively (Beck et al., 1988).

The BDI was adapted for Iranian culture. According to Modabber-Nia et al. (2007) and Beck et al. (1988) standardized questionnaire scores are defined as follows:

- $\quad$ Symptom-free or normal (0-15)

- $\quad$ Mild depression (16-30)

- Moderate depression (31-46)

- $\quad$ Severe depression (47-63)

Based on the rules of the Ministry of Education in Iran, the range of academic achievement (GPA) is from 0-20 and includes 4 parts. From 0-9 is considered fail that is if an Iranian student gets this range of score in any of the courses, she/he fails. A score of 10-14.99 is considered weak while score of 15-16.99 is considered moderate and a score of 17-20 is considered excellent. Students were also asked about their last year cumulative academic achievement (0.00-20.00).

A descriptive statistical analysis (frequency, percentage, means and standard deviations) was done to characterize the depression, academic achievement and gender. A Pearson correlation was calculated to evaluate the level of significance of the relationship between the depression score and academic achievement and also the Pearson correlation was used to determine the significance of the relationship between age and academic Achievement. In addition, a T-test was done to test the relationship between gender and academic achievement which means that academic achievement was used as an interval variable not a category and also t-test was conducted to test gender with depression.

\section{RESULTS}

Table 1 show that the number of the respondents in the current study includes $200(50 \%)$ males and 200 $(50 \%)$ females. The age range of the respondents is $15-$ 19 years and the sample is divided into three age categories: $43.5 \%$ aged $15-16,38.5 \%$ aged $17-18$ and the last group, $17 \%$ aged 19 years. Of the respondents $3 \%$ reported their academic achievement being less than 9.99, while 43.8, 26.2 and $27 \%$ of them reported their academic achievement to be 10-14.99, 15-16.99 and more than 17 respectively.

In addition, results of the study showed that $70.5 \%$ of the respondents were symptom-free or normal, while $22.3 \%$ were mildly depressed, $3 \%$ were moderately depressed and $2.8 \%$ had severe depression.

Table 2 displays the significant relationship between depression, age and the respondents' academic achievement. The Pearson correlation formula was used to analyze academic achievement as the dependent variable and depression as the independent variable. The results are summarized in Table 2. Depression and academic achievement were found to be significantly correlated $(\mathrm{r}=0.23, \mathrm{p} \leq 0.000)$, therefore there was a significant relationship between depression and academic achievement.

In addition, the data showed that age and academic achievement were significantly correlated $(r=0.23$, $\mathrm{p} \leq 0.000$ ), therefore there was a significant relationship between age and academic achievement among the respondents.

Table 1: Academic achievement by target variables among respondents

Academic achievement levels

\begin{tabular}{|c|c|c|c|c|c|c|c|c|c|}
\hline \multirow[t]{2}{*}{ Depression levels } & \multicolumn{2}{|c|}{$<9.99$} & \multicolumn{2}{|c|}{$10-14.99$} & \multicolumn{2}{|c|}{$15-16.99$} & \multicolumn{2}{|c|}{$>17.0$} & \multirow[b]{2}{*}{ Total } \\
\hline & $\mathrm{n}$ & Percentage & $\mathrm{n}$ & Percentage & $\mathrm{n}$ & Percentage & $\mathrm{n}$ & Percentage & \\
\hline Normal (0-15) & 7 & 2.5 & 110 & 39.0 & 76 & 27.0 & 89 & 31.6 & 282 \\
\hline Mild (16-30) & 4 & 4.2 & 49 & 51.6 & 26 & 27.4 & 16 & 16.8 & 95 \\
\hline Moderate (31-46) & 1 & 8.3 & 7 & 58.3 & 21 & 16.7 & 2 & 16.7 & 12 \\
\hline Severe (47-63) & 0 & 0.0 & 9 & 81.8 & 1 & 9.1 & 1 & 9.1 & 11 \\
\hline \multicolumn{10}{|l|}{ Age group } \\
\hline $15-16$ & 0 & 0.0 & 46 & 26.4 & 48 & 27.6 & 80 & 46.0 & 174 \\
\hline $17-18$ & 3 & 1.9 & 80 & 51.6 & 47 & 30.3 & 25 & 16.1 & 155 \\
\hline 19 & 9 & 12.7 & 49 & 69.0 & 10 & 4.1 & 3 & 4.2 & 71 \\
\hline \multicolumn{10}{|l|}{ Gender } \\
\hline Male & 10 & 5.0 & 102 & 51.0 & 47 & 23.5 & 41 & 20.5 & 200 \\
\hline Female & 2 & 1.0 & 73 & 36.5 & 58 & 29.0 & 67 & 3.5 & 200 \\
\hline
\end{tabular}


Table 2: Pearson Correlation between depression and academic achievement $(n=400)$

\begin{tabular}{|c|c|c|c|c|}
\hline \multirow[b]{2}{*}{ Variables } & \multicolumn{4}{|c|}{ Academic achievement } \\
\hline & $\mathrm{r}$ & & & $\mathrm{p}$ \\
\hline Depression & $-0.22 * *$ & & & 0.000 \\
\hline Age & $0.23 * *$ & & & 0.000 \\
\hline \multicolumn{5}{|c|}{ Note: $\mathrm{p} \leq 0.01$} \\
\hline \multicolumn{3}{|c|}{ Table 3: T-test of academic achievement between male and female } & & \\
\hline & Mean & SD & $\mathrm{t}$ & $\mathrm{p}$ \\
\hline Gender & & & -5.47 & 0.000 \\
\hline Male & 14.45 & 2.46 & & \\
\hline Female & 15.74 & 2.21 & & \\
\hline
\end{tabular}

Note: $\mathrm{p} \leq 0.01$

In order to display the significant difference between the factor of gender and the respondents' academic achievement, a t-test was run. Females $(\mathrm{M}=15.74, \mathrm{SD}=2.46)$ reported significantly higher academic achievement than males $(M=15.74$, $\mathrm{SD}=2.21),(\mathrm{t}(1)=-5.47, \mathrm{p}=0.000)($ Table 3$)$. There was a remarkable difference at the 0.05 level of significance, determining that there is a statistically significant difference between the mean of the two groups and their academic achievement. Evidently, there was significant difference of academic achievement gender respondents.

\section{DISCUSSION}

Forty three point eight and $3 \%$ of respondents in the current study were weak and fail respectively in 2008, Data from the current study differed from the findings of Daskzan (2004); Mozaffari (2001) and Nosrati Shoar (2003). The discrepancy may be related to such matters as different sample size and motivation of students to study.

The results from the present study showed depression affected academic achievement $(r=0.23$, $\mathrm{p} \leq 0.000$ ). These findings confirm other findings reported in the literature that shows adolescents with depression being vulnerable to educational underachievement. Also, based on a resource allocation model of the effect of depressed mood on cognition, it has been found that students with symptoms of depression are predisposed to focusing their attention on interfering, irrelevant thoughts, leaving little sustained attention available for cognitive tasks, which then leads to academic failure. As many of the school activities and homework depend on the ability to sustain attention and concentration, depression, which disrupts concentration and attention in school, is likely to undermine academic performance. Also, research has indicated that depressed mood is negatively related to academic achievement (Chen et al., 2000).
Depression is one of the mental disorders which cause many problems for society, especially depression in high school students. The current study showed that around $30 \%$ of respondents were depressed. This result, however, is different from the results of other research, for instance that of Hallfors et al. (2005) and the 2004 National Survey on Drug Use and Health, in which it was estimated that $14 \%$ of adolescents aged 12-17 had experienced at least MDE in their lifetime and an estimated $9.0 \%$ of them had experienced at least one MDE in the past year. Adolescents aged 16 or 17 were more than twice as likely to report earlier MDE compared to those aged 12 or 13 (12.3 Vs 5.4\%).The results of the current study, also, differ from those of Modabber-Nia et al. (2006); Hosseini and Mousavi (2004); Masood Zadeh (2002), who indicated that 34, 44.3 and $39.1 \%$ of high schools' students in Iran had depression, respectively. The discrepancy may be related to using different tools for measurement of depression, different sample sizes, the motivation of respondents to responding and the subjects' lifestyle.

It is important to note that the rate of depression among high school students in the current study and in the other Iranian studies (Modabber-Nia et al., 2007; Hossaini and Mousavi, 2004; Masood Zadeh, 2002) also, was greater than the rates evident in other countries where research on this topic has been carried out, this difference may be related to cultural differences relating to psychosocial stress and the different understanding and use of concepts such as self evaluation, social self-confidence and adaptive behavioral styles (Modabber-Nia et al., 2007). It also, may be related to the type of thoughts the adolescent respondents had regarding the self and the world. For example, based on the Beck et al. (1988) depression theory, a negative view about oneself, the future and the world leads to low self esteem, hopelessness and depression.

The results from the present study indicated that age and academic achievement were significantly correlated $(\mathrm{r}=0.23, \mathrm{p} \leq 0.000)$ and this finding is in agreement with the Anne-Rampacher and Peterson (1999), who reported that there is a significant difference between age subgroups and academic achievement.

There are, no doubt, many reasons for age having an impact on academic achievement. One of the important reasons, based on the research reported in the literature, is maturation; mature-age students have a better school performance than adolescents' school performance (McManus and Richards, 1986; AnneRampacher and Peterson, 1999). 
Data from the current study showed that there is a significant deference between gender and academic achievement. This finding confirm with Fergusson and Horwood (1997) and Linver et al. (2002). They indicated gender impact on academic achievement among respondents.

\section{CONCLUSION}

Depression was found to have an impact on academic achievement among adolescents. It decreased academic achievement. It could also decrease motivation in ability attention, concentration and leads to academic failure. These data have provided evidence of a relationship between depression and academic achievement among high school adolescents in response; it is proposed that selective preventive activities be introduced at high schools for students with academic problems. Mental health can be developed in school settings with the aid of support strategies such as counseling, teach life skill programs and psychotherapy.

\section{ACKNOWLEDGEMENT}

We would like to thank the Organization of Education of Kurdistan province, Iran for giving us the official letter that allowed us to do the data collection among high school students in Sanandaj and, also, thanks to the high school students for participating in this study.

\section{REFERENCES}

Anne-Rampacher, K. and C. Peterson, 1999. Effects of gender and age on students' performance in adjective technique classes. Eur. J. Chiropract. Educ., 13: 114-130.

American Psychiatric Association, 2009. Diagnostic and Statistical Manual of Mental Disorders (DSMIV). 6th Edn., American Psychiatric Association, New York, ISBN: 10: 1433805618, pp: 272.

Beck, A.T., R.A. Steer and M.G. Garbin, 1988. Psychometric properties of the Beck depression inventory: Twenty-five years of evaluation. Clin. Psychol. Rev., 8: 77-100.

Chen, X. and B.S. Li, 2000. Depression mood in Chinese children: Development significance for social and school adjustment. Int. J. Behav. Dev., 24:472-479.

Daskzan, J., 2004. Prevalence of test-anxiety and its' related to academic problems. Research Center of Organization Education in Kurdistan Province.
Fergusson, D.M. and L.J. Horwood, 1997. Gender differences in educational achievement in a New Zealand birth cohort, Zealand birth cohort. N. Z. J. Educ. Stud., 32: 83-96.

Frojd, S.A., E.S. Nissinen, M.U.I. Pelkonen, M.J. Marttuenb and A.M. Koivisto et al., 2008. Depression and school performance in middle adolescent boys and girls. J. Adolescence, 31: 485-498. DOI: 10.1016/j.adolescence.2007.08.006

Groth-Marnat, G., 2003. The handbook of psychological assessment. 1st Edn., John Wiley and Sons, New York, ISBN: 10: 0471419796, pp: 862.

Gravette, F.J. and L.B. Forzano, 2006. Research Methods for the Behavioral Science. 1st Edn., Wadsworth Pub. Co., Australia, ISBN: 10: 053454911X, pp: 478.

Hallfors, D.D., M.W. Waller, D. Bauer, C.A. Ford and C.T. Halpern, 2005. Adolescence, sex and drugs or depression. Am. J. Prev. Med., 29: 163-170.

Hosseini, S.H. and S.E. Mousavi, 2004. Mental-Health Status of Newly-Admitted Students of the Mazandaran University of Medical Sciences in the 1999-2000 Academic Year, Nov. 2004, Published Online, pp: 6-7.

Khayerabadi, G. and F. Yousefi, 2000. Mental health among high school students in Kurdistan province scientific and research. J. Kurdistan Med. Sci. Univ., 5: 12-20.

Linver, M.R. P.E. Davis-Kean and G.S. Eccles, 2002. Influences of Gender on Academic Achievement. Proceeding of the Biennial Meetings of the Society for Research on Adolescence, (BMSRS' 02), New Orleans, LA., pp: 1-14.

Masood Zadeh, M., 2002. Mental health among high school students in Sarri city-Iran. Sci. J. Mazendarran Med. Sci. Uni., 14: 45-55.

Mackenzie, D.L., A.R. Gover, G.S. Armstrong and O. Mitchell, 2001. A national study comparing the environments of boot camps with traditional facilities for juvenile offenders. National Institute of Justice. http://www.ncjrs.gov/pdffiles1/nij/187680.pdf

Modabber-Nia, J.M., H.S. Tehrani, S.R. Moosavi, N.J. Asli and M. Fallahi, 2007. The prevalence of depression among high School and pre-university adolescents in Rasht, Iran. Arch. Iran. Med., 10: 141-146.

Moritz, S., M. Kloss, H. Jahn, M. Schick and I. Hand, 2003. Impact of co-morbid depressive symptoms on non-verbal memory and visuospatial performance in obsessive-compulsive disorder. J. Cognit. Neuropsychiatry, 8: 261-272. DOI: $10.1080 / 135468000344000020$ 
McManus, I.C. and P. Richards, 1986. Prospective survey of performance of medical students during preclinical years. Br. Med. J., 293: 124-127.

Mozaffari, M.R., 2001. Rate of affective-family and educational problems between Shaheds' high school students and none Shaheds'high school students in Sanandaj. Organization Education of Kurdistan.

Nosrati Shoar, M., 2003. Causality of academic problems among elementary school students in Kurdistan-Iran. Organization Education.

Sharifi, F., 2001. Causing depression among high school students in Sanandaj. Research Center of Office of Education in Kurdistan Province.
Tavakeli, M.B., 2000. Prevalence of depression and anxiety among high school students in Kurdistan. Research Center of Organization of Education in Kurdistan Province.

Winter, M.G. and C.D. Bowers, 2007. Peer relationships and academic achievement as interacting predictors of depressive symptoms during middle childhood. Can. J. Behav. Sci., 39: 220-234. DOI: 10.1037/cjbs2007017 